\title{
Distinctive Anatomical Patterns of Gene Expression for cGMP-inhibited Cyclic Nucleotide Phosphodiesterases
}

\author{
Rickey R. Reinhardt, Edward Chin, Jian Zhou, Masato Taira, * Taku Murata, * Vincent C. Manganiello, * \\ and Carolyn A. Bondy \\ Developmental Endocrinology Branch, National Institute of Child Health and Human Development; and *Pulmonary/Critical Care \\ Medicine Branch, National Heart, Lung, and Blood Institute, National Institutes of Health, Bethesda, Maryland 20892
}

\begin{abstract}
Type III cGMP-inhibited phosphodiesterases (PDE3s) play important roles in hormonal regulation of lipolysis, platelet aggregation, myocardial contractility, and smooth muscle relaxation. We have recently characterized two PDE3 subtypes (PDE3A and PDE3B) as products of distinct but related genes. To elucidate their biological roles, in this study we compare cellular patterns of gene expression for these two enzymes during rat embryonic and postnatal development using in situ hybridization. PDE3A mRNA is abundant in adipose tissue and is also expressed in hepatocytes throughout development. This mRNA is also highly abundant in embryonic neuroepithelium including the neural retina, but expression is greatly reduced in the mature nervous system. Finally, PDE3A mRNA is localized in spermatocytes and renal collecting duct epithelium in adult rats.

PDE3B mRNA is highly expressed in the cardiovascular system, including myocardium and arterial and venous smooth muscle, throughout development. It is also abundant in bronchial, genitourinary and gastrointestinal smooth muscle and epithelium, megakaryocytes, and oocytes. PDE3B mRNA demonstrates a complex, developmentally regulated pattern of gene expression in the central nervous system. In summary, the two different PDE3s show distinctive tissue-specific patterns of gene expression suggesting that PDE3A is involved in hormonal regulation of lipolysis and glycogenolysis, while regulation of myocardial and smooth muscle contractility appears to be a function of PDE3B. In addition, the present findings suggest previously unsuspected roles for these enzymes in gametogenesis and neural development. (J. Clin. Invest. 1995. 95:1528-1538.) Key words: cyclic nucleotide phosphodiesterase - PDE3 CGMP • CAMP • mRNA
\end{abstract}

\section{Introduction}

Cyclic nucleotide phosphodiesterases (PDEs) ${ }^{1}$ are critical determinants of intracellular cyclic nucleotide concentrations and, consequently, of biological processes mediated by these important second messengers $(1,2)$. There are at least seven distinct mam-

Address correspondence to Rickey R. Reinhardt, National Institutes of Health, Building 10, Room 10N-262, Bethesda, MD 20892. Phone: 301496-6664; FAX: 301-402-0574.

Received for publication 13 October 1994 and in revised form 30 November 1994.

1. Abbreviation used in this paper: PDE, phosphodiesterase.

The Journal of Clinical Investigation, Inc.

Volume 95, April 1995, 1528-1538 malian PDE gene families which differ in biochemical and physical properties, responses to specific effectors, inhibitors and therapeutic agents, and regulatory control mechanisms (1-3). PDEs share a common domain organization pattern, all containing conserved catalytic domains of $\sim 270$ amino acids (usually in the $\mathrm{COOH}$-terminal regions) with divergent $\mathrm{NH}_{2}$-terminal domains (1-4). Most of the PDE gene families contain at least two subfamilies which are products of distinct but related genes or which arise by alternative splicing or differentially regulated transcription initiation mechanisms. For example, five different type I calmodulin-sensitive (5-7) and four type IV cAMP-specific $(8,9)$ PDE subfamilies have been identified. Although in some instances specific PDEs are relatively highly concentrated in individual cells, such as a type II cGMP-stimulated PDE in bovine adrenal glomerulosa cells (10), multiple PDE types are usually present in most cells, in different amounts, proportions, and subcellular locations $(1,2)$. Thus, intracellular cyclic nucleotide hydrolysis is a regulated process dependent on the coordinated and integrated activities of several structurally related but differentially expressed and regulated PDE isoenzymes.

Type III PDEs (PDE3s), commonly referred to as cGMPinhibited cyclic nucleotide phosphodiesterases (11), have been isolated from a number of tissues, including adipose tissue (12), platelets (13), myocardium (14), vascular $(15,16)$ and tracheo-bronchial $(17,18)$ smooth muscle preparations, liver $(19$, 20), placenta (21), and lymphocytes (22). PDE3s are characterized by a high affinity for cAMP and cGMP, with the $V_{\max }$ higher for cAMP. Hydrolysis of cAMP by PDE3s is potently inhibited by cGMP, cilostamide, and a number of compounds, such as milrinone and enoximone, with inotropic/vasodilatory/ antiplatelet aggregatory properties $(11,23-27)$. The subcellular distribution of PDE3s varies, with the enzyme predominantly microsomal in adipocytes $(11,12,28,29)$ and liver $(19,20)$, cytosolic in platelets $(13,30)$, and both cytosolic and membrane-associated in myocardium (31-33). In rat adipocytes, activation of a particulate PDE3 is an important component in the antilipolytic action of insulin $(11,12,28,29,34,35)$. Results from various studies using specific PDE3 inhibitors and cAMP analogues suggest that PDE3s regulate cAMP pools involved in the hormonal control of lipolysis, glycogenolysis, myocardial contractility, smooth muscle relaxation, and platelet aggregation $(11,14,16-18,23-27,30,31,34-37)$. It has also been suggested that in certain cells, e.g., platelets and lymphocytes, some effects of nitric oxide, which activates guanyl cyclase to increase cGMP, are mediated via increases in cAMP brought about by cGMP-inhibition of PDE3s $(38,39)$.

We have cloned cDNAs for two cGMP-inhibited cyclic nucleotide phosphodiesterases $(40,41)$, which in accord with the desire to develop a common nomenclature in this field, we will refer to as PDE3A and PDE3B. These enzymes are products of distinct but related genes; PDE3A mRNA is highly expressed in rat adipocytes, whereas PDE3B mRNA is highly expressed 

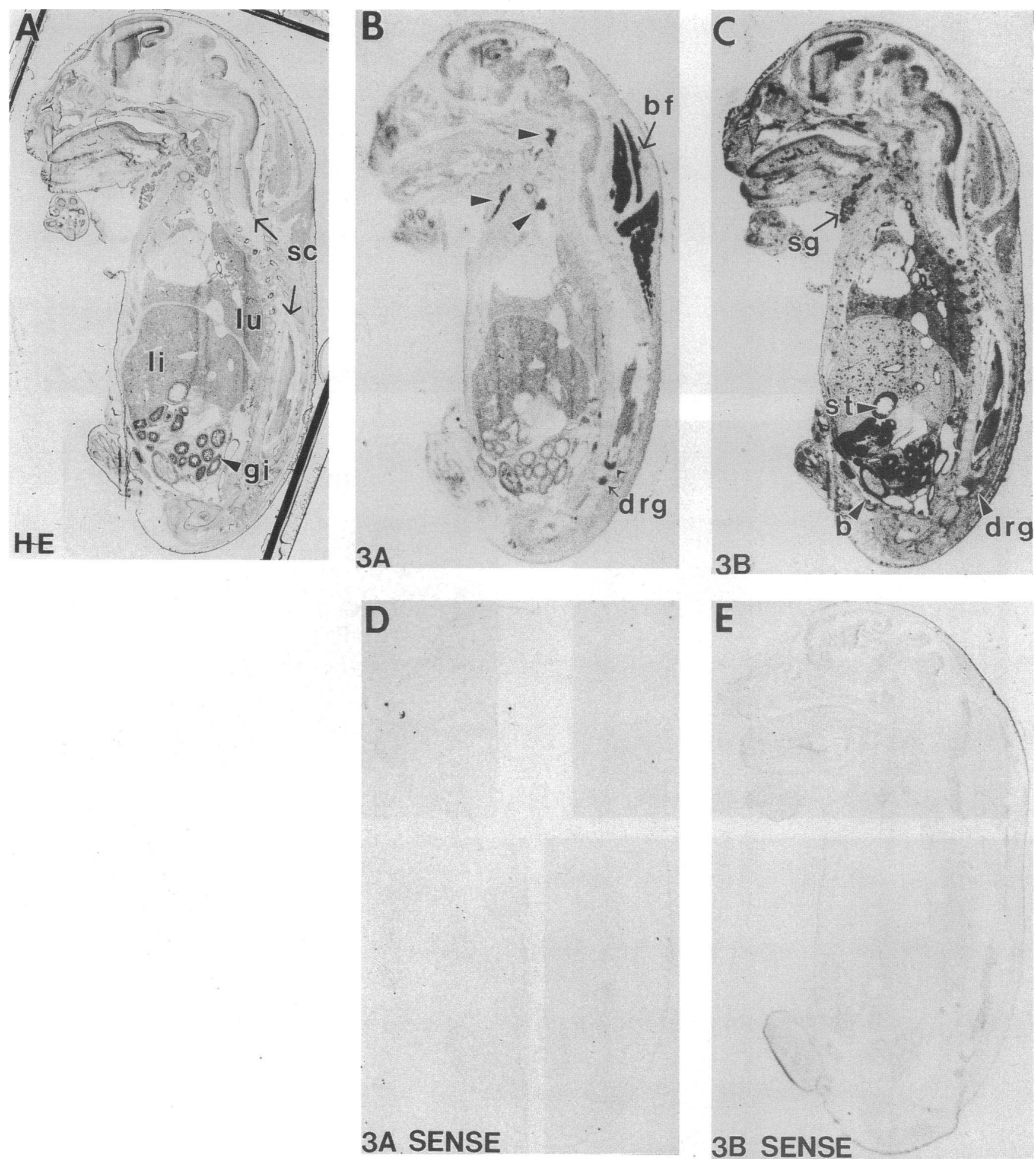

Figure 1. PDE3A and PDE3B demonstrate distinctive patterns of gene expression in the rat fetus. A sagittal section through an embryonic day 20 (E20) fetus stained with hematoxylin and eosin $(H E)$ is shown in $A$. That section and adjacent serial sections were hybridized to PDE3A antisense $(B)$ or sense $(D)$ and PDE3B antisense $(C)$ or sense $(E)$ probes, and the resulting hybridization patterns are shown in film autoradiographs. PDE3A mRNA is most abundant in adipose tissue, including the brown fat $(b f)$ of the dorsal fat pad and also in collections of white fat (arrowheads). PDE3B mRNA is most abundant in the gastrointestinal ( $g i$ ) and cardiovascular systems. The heart is not included in these sections, but the PDE3B hybrids in the vasculature appear as pockmarks throughout embryonic tissues. Both transcripts are relatively plentiful in the dorsal root ganglia $(d r g)$, bladder $(b)$, liver $(l i)$, lung $(l u)$, spinal cord $(s c)$, submandibular gland $(s g)$, and stomach $(s t)$.

in rat cardiac tissue (41). To better understand biological roles of the two PDE3 subtypes, we have used in situ hybridization to investigate cellular patterns of PDE3A and PDE3B gene expression during embryonic and postnatal development in the rat. Our results show that PDE3A and PDE3B mRNAs exhibit unique and distinctive spatiotemporal patterns of expression, supporting the view that each of these two enzymes serves a cell- and developmental stage-specific biological role. 

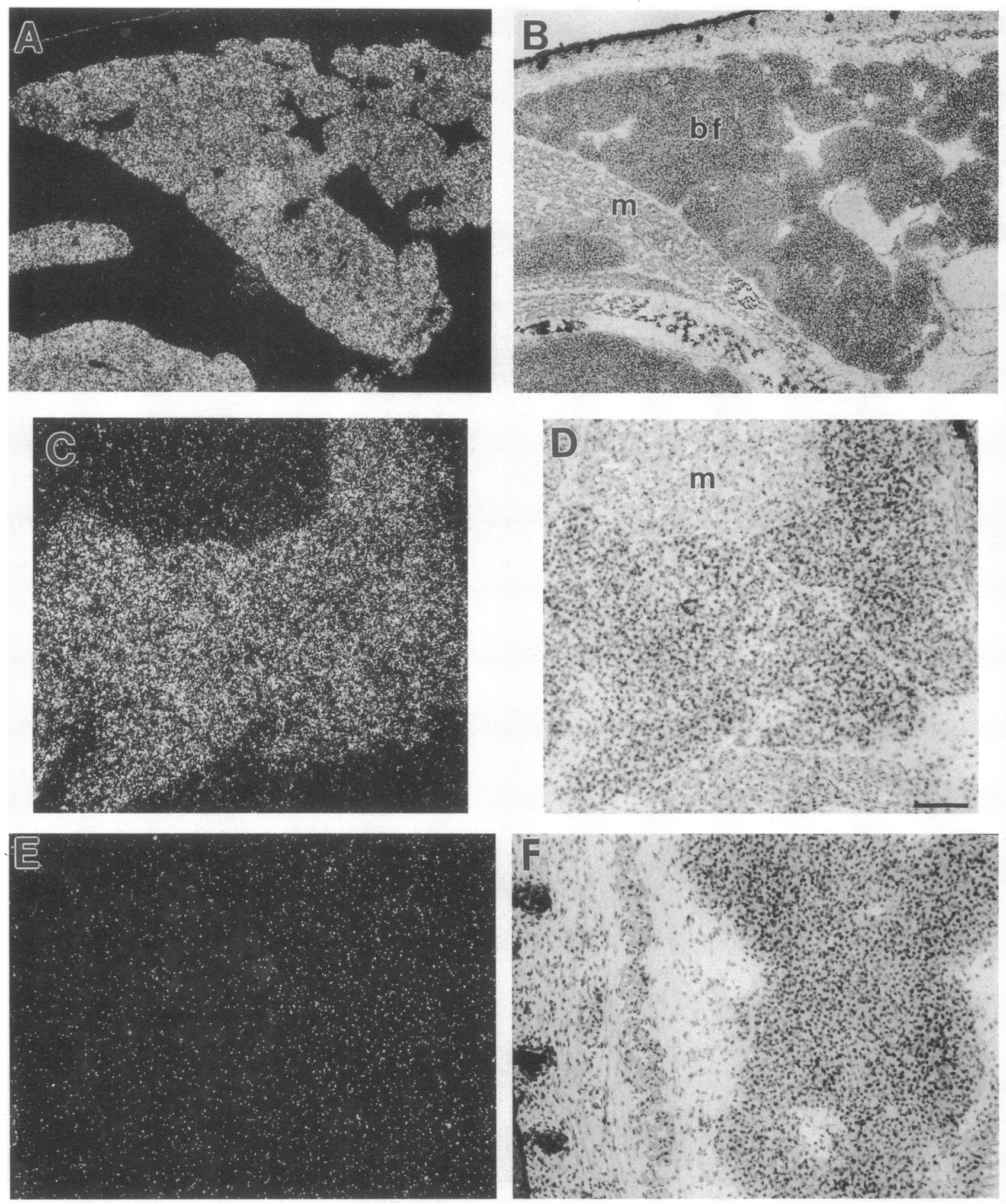

Figure 2. PDE3A mRNA is abundant in brown $(A$ and $B)$ and white $(C$ and $D)$ adipose tissue. Hybridization is shown in paired dark- (left) and bright-field (right) micrographs. Hybridization signals appear as white grains in the dark field. $E$ and $F$ show control sense PDE3A probe hybridization signal produced by hybridization, wash, and exposure in the same batch with the PDE3A antisense slides. $b f$, brown fat; $m$, muscle. Bar $=200$ $\mu \mathrm{m}$ for $A$ and $B$ and $100 \mu \mathrm{m}$ for $C-F$.

\section{Methods}

Tissue. Sprague-Dawley rats were obtained from Taconic Farms (Germantown, NY) and used in a protocol approved by the National Institute of Child Health and Human Development Animal Use Committee. Rats were decapitated after carbon dioxide anesthesia and tissues were removed and immediately frozen over dry ice before sectioning on a cryostat at a thickness of $10 \mu \mathrm{m}$. Timed pregnant dams were obtained 

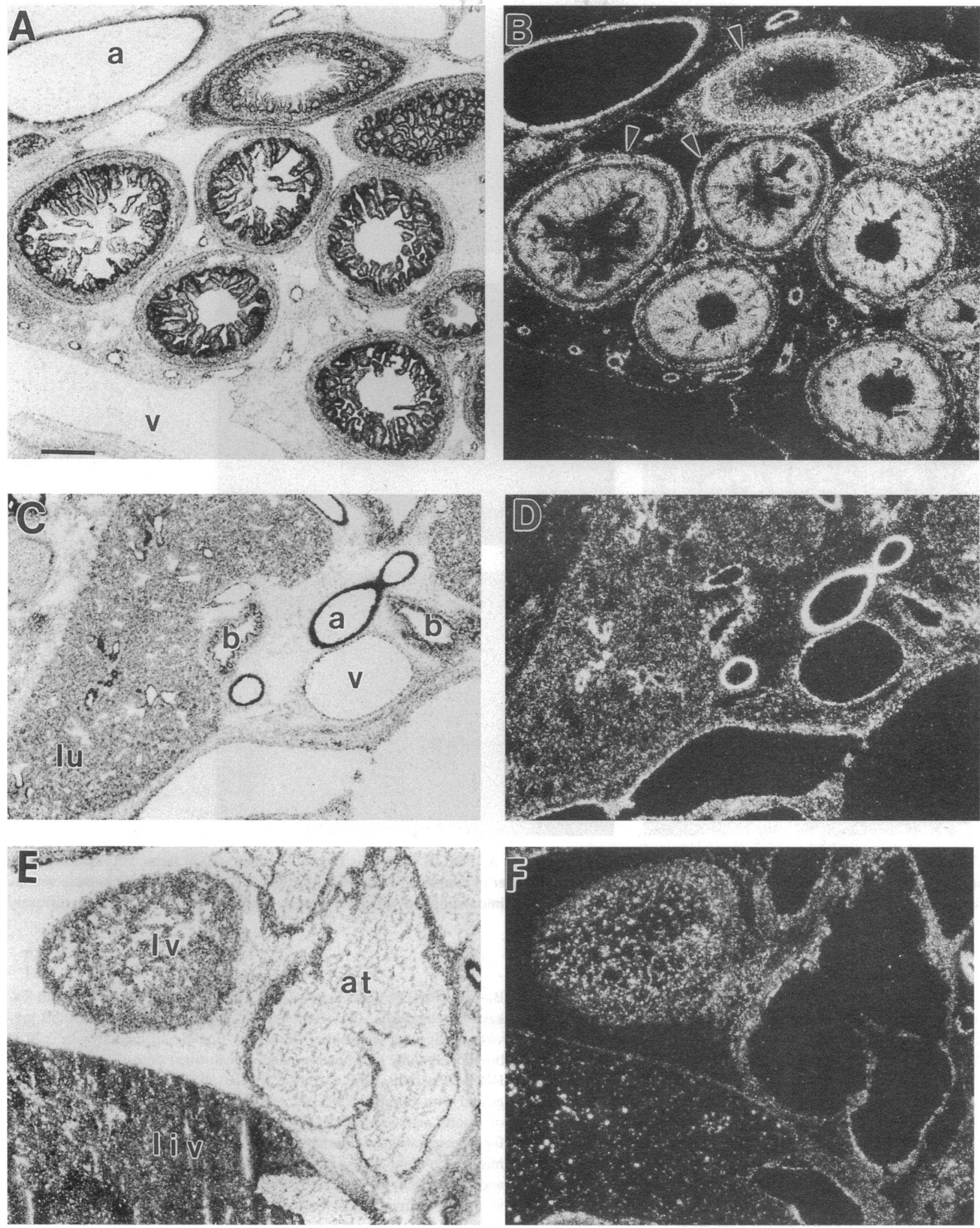

Figure 3. PDE3B gene expression in developing viscera. PDE3B mRNA is concentrated in gut epithelium and surrounding smooth muscle (arrowheads in $A$ and $B$ ), the vasculature, including arteries $(a)$ and veins $(v)$, bronchi $(b)(C$ and $D)$, and heart $(E$ and $F)$. Note the bright white dots in the liver ( $l i v$ in $E$ and $F$ ) which are due to hybridization in single large cells. These paired bright- and dark-field micrographs are from E20 $(A-D)$ and E15 $(E$ and $F)$ embryos. at, atrial chamber; $l v$, left ventricle. Bar $=200 \mu \mathrm{m}$.

at 15,18 , and $20 \mathrm{~d}$ of gestation for the evaluation of fetal mRNA expression. Developmental studies were continued using tissues obtained from rats at 5 and $20 \mathrm{~d}$ of age as well as adults (60-75-d old). Tissues from a minimum of two animals at every time point were examined. Frozen sections were thaw mounted onto poly-L-lysinecoated slides and stored at $-70^{\circ} \mathrm{C}$ until use.

$P D E 3$ probes used for in situ hybridization. Regions in the regulatory domains of the full length rat PDE3A (nt 754-1923) and PDE3B 

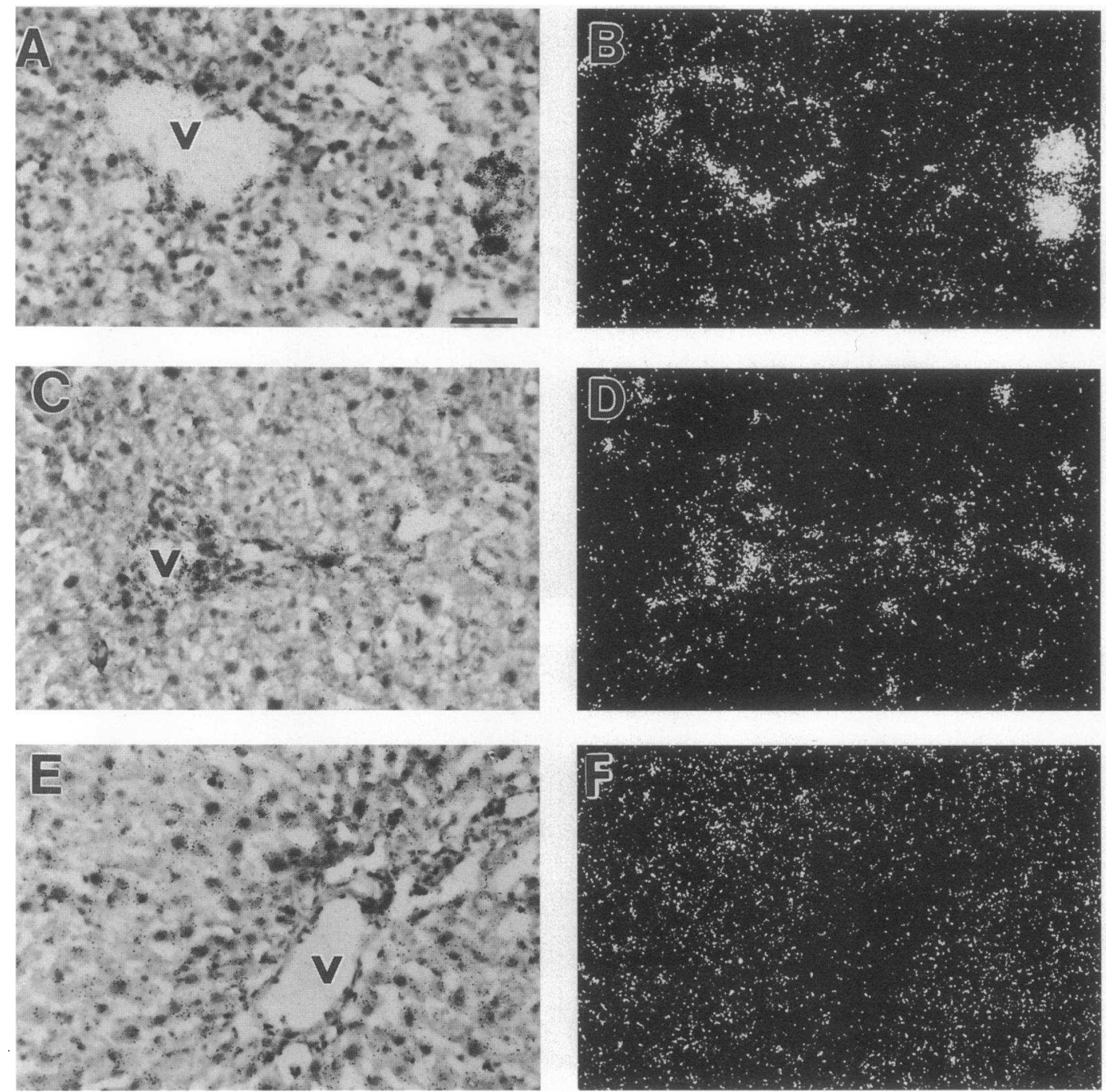

Figure 4. During embryonic development and up to postnatal day 5 ( $A$ and $B$ ) PDE3B mRNA is focally concentrated in large cells scattered throughout the liver; these presumed megakaryocytes are absent from the liver in adulthood when PDE3B mRNA is detected only in hepatic venous and sinusoidal endothelium $(C$ and $D)$. In contrast, from early development into adulthood without evidence of change, PDE3A mRNA is diffusely localized in hepatocytes $(E$ and $F)$. $v$, vein. Bar $=100 \mu \mathrm{m}$.

(nt 844-2200) cDNAs, which share little homology (reference 41 and our unpublished observations), were amplified using the PCR technique in a total volume of $100 \mu \mathrm{l}$ containing $20 \mathrm{mM}$ Tris $\mathrm{HCl}, \mathrm{pH} 8.2,200$ $\mu \mathrm{M}$ dNTPs, $10 \mathrm{mM} \mathrm{KCl}, 6 \mathrm{mM}\left(\mathrm{NH}_{4}\right)_{2} \mathrm{SO}_{4}, 2 \mathrm{mM} \mathrm{MgCl}_{2}, 0.1 \%$ Triton $\mathrm{X}-100,10 \mu \mathrm{g} / \mathrm{ml}$ nuclease free $\mathrm{BSA}$, and $2.5 \mathrm{U}$ PFU DNA polymerase (Stratagene La Jolla, CA) in a GeneAmp PCR System 9600 (PerkinElmer Corp., Norwalk, $\mathrm{CT}$ ) under the following conditions: denaturation at $98^{\circ} \mathrm{C}(15 \mathrm{~s})$, and extension with annealing $(30 \mathrm{~s})$ at $66,64,62$, and $60^{\circ} \mathrm{C}$ for 2 cycles each, at $58^{\circ} \mathrm{C}$ for 28 cycles, and with final extension at $72^{\circ} \mathrm{C}$ for $10 \mathrm{~min}$. For the PDE3A fragment, $10 \mathrm{ng}$ of the full length PDE3A in pBluescript was used as template with $100 \mathrm{ng}$ forward primer, 5' GCGGATCCCCACGTCCGGGGAGCCTCACC (corresponding to nt 754-773 with BamHI site) and $100 \mathrm{ng}$ reverse primer, 5' CCGGATCCCAATAACACTTCCTGGTCAAT (corresponding to nt 1923-1943 [41] with BamHI site). For the PDE3B fragment, $10 \mathrm{ng}$ of the full length PDE3B in pBluescript was used as template, with $100 \mathrm{ng}$ forward primer, 5' GGGAATTCCTGGTTTCTCTGGAGAGGTTC (corresponding to nt $844-864$, with EcoRI site) and $100 \mathrm{ng}$ reverse primer, 5' GGGAATTCTGGAGCAAGAATTGGTTTGTC (corresponding to nt 2179-2200 with EcoRI site).

PDE3A and PDE3B fragments, purified by electrophoresis in $1 \%$ low melting point agarose and phenol extraction, were digested with
BamHI (PDE3A) and EcoRI (PDE3B), ligated (ligation kit from Takara Biochemicals, Inc., Berkeley, CA) into pBluescript plasmid previously digested with either BamHI or EcoRI and treated with $0.22 \mathrm{U}$ bovine alkaline phosphatase, and transformed into Escherichia coli DH5 $\alpha$. Plasmids were extracted by the alkaline lysis method and digested with BamHI (PDE3A) or EcoRI (PDE3B) to verify the length of inserts and with Xhol (PDE3A) or with SacII and NdeI (PDE3B) for determination of orientation of inserts. For linearization of the plasmids, each clone was digested with SaII for sense or SpeI for antisense and were used for in situ hybridization. These two antisense probes identified distinct bands when used in Northern hybridization (data not shown).

In situ hybridization. The synthesis of ${ }^{35} \mathrm{~S}$-labeled cRNA probes and in situ hybridization protocol has been previously described (42). In brief, high specific activity, double-labeled cRNA probes were synthesized in $10-\mu \mathrm{l}$ reactions containing $100 \mu \mathrm{Ci}{ }^{35} \mathrm{~S}$-CTP and $100 \mu \mathrm{Ci}{ }^{35} \mathrm{~S}$ UTP, $10 \mathrm{mM} \mathrm{NaCl}, 6 \mathrm{mM} \mathrm{MgCl} 2,40 \mathrm{mM}$ Tris (pH 7.5), $2 \mathrm{mM}$ spermidine, $10 \mathrm{mM}$ DTT, $500 \mu \mathrm{M}$ each unlabeled ATP and GTP, 25 $\mu \mathrm{M}$ each unlabeled UTP and CTP, $500 \mathrm{ng}$ linearized template, $15 \mathrm{U}$ of the appropriate polymerase, and $15 \mathrm{U}$ RNasin (enzymes and other molecular biology reagents were obtained from Promega Corp., Madison, WI). The reaction was incubated at $42^{\circ} \mathrm{C}$ for $60 \mathrm{~min}$, after which 

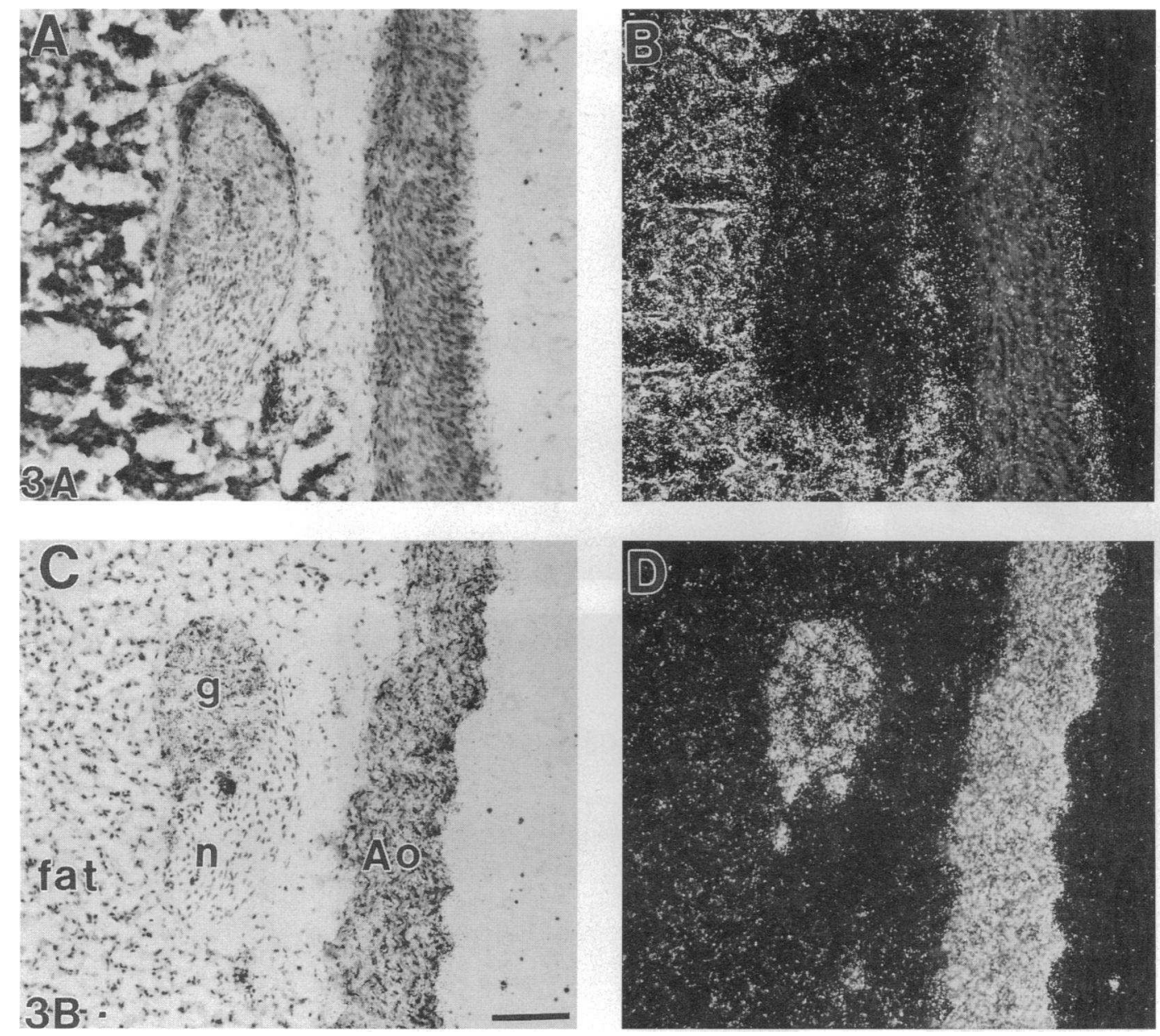

Figure 5. Comparison of PDE3A ( $A$ and $B$ ) and PDE3B $(C$ and $D$ ) in adult aorta and periaortic fat. PDE3B mRNA is highly abundant in smooth muscle and endothelium of the aorta $(A o)$ and is also highly expressed in the autonomic ganglion $(g)$ embedded in connective tissue next to the aorta. PDE3A mRNA is selectively localized in the periaortic fat, where the hybridization is so strong that the fat cells look black with exposed silver grains. Bar $=100 \mu \mathrm{m}$.

the DNA template was removed by digestion with DNase I at $37^{\circ} \mathrm{C}$ for 10 min. Radiolabeled cRNA was separated from unincorporated nucleotides with sterile gel chromatography spin columns (Bio Spin 6; Bio-Rad Laboratories, Richmond, CA), precipitated with $5 \mu$ l tRNA $(10 \mu \mathrm{g} / \mathrm{ml}), 10 \mu \mathrm{l} \mathrm{NaCl}(5 \mathrm{M}), 10 \mu \mathrm{l}$ DPEC$-\mathrm{H}_{2} \mathrm{O}$, and $300 \mu \mathrm{l}$ cold ethanol, frozen on dry ice for $30 \mathrm{~min}$, and centrifuged $(10,000 \mathrm{~g}, 30$ $\min$ at $4^{\circ} \mathrm{C}$ ). The purified probes were shortened to an average length of $\sim 150$ bases by controlled alkaline hydrolysis. Average specific activity of probes generated by this protocol was $2-3 \times 10^{8} \mathrm{dpm} / \mu \mathrm{g}$. Before hybridization, sections were warmed to $25^{\circ} \mathrm{C}$, fixed in $4 \%$ formaldehyde, and soaked for $10 \mathrm{~min}$ in $0.25 \%$ acetic anhydride $/ 0.1 \mathrm{M}$ triethanolamine hydrochloride $/ 0.9 \% \mathrm{NaCl}$. Tissue was dehydrated through an ethanol series, dilipidated in chloroform, rehydrated, and air-dried. ${ }^{35} \mathrm{~S}$-labeled probes were added to hybridization buffer $\left(10^{7} \mathrm{cpm} / \mathrm{ml}\right)$ composed of $50 \%$ formamide, $0.3 \mathrm{M} \mathrm{NaCl}, 20 \mathrm{mM}$ Tris- $\mathrm{HCl}, \mathrm{pH} 8,5 \mathrm{mM}$ EDTA, $500 \mu \mathrm{g}$ tRNA $/ \mathrm{ml}, 10 \%$ dextran sulfate, $10 \mathrm{mM}$ dithiothreitol, and $0.2 \%$ each of BSA, Ficoll, and polyvinylpyrollidone. Hybridization buffer was added to slides which were coverslipped and placed in humidified chambers overnight $(14 \mathrm{~h})$ at $55^{\circ} \mathrm{C}$. Slides were washed several times in $4 \times$ SSC to remove cover slips and hybridization buffer, dehydrated and immersed in $0.3 \mathrm{M} \mathrm{NaCl}, 50 \%$ formamide, $20 \mathrm{mM}$ Tris- $\mathrm{HCl}, 1$ $\mathrm{mM}$ EDTA at $60^{\circ} \mathrm{C}$ for $15 \mathrm{~min}$. Sections were then treated with RNase A $(20 \mu \mathrm{g} / \mathrm{ml})$ for $30 \mathrm{~min}$ at $37^{\circ} \mathrm{C}$, passed through graded salt solutions $(2 \times, 1 \times$, and $0.5 \times$ SSC), followed by a $15-$ min wash in $0.1 \times$ SSC at $50^{\circ} \mathrm{C}$. Slides were air dried and apposed to Hyperfilm-beta Max (Amersham Corp., Arlington Heights, IL) for 3-6 d and then dipped in Kodak NTB2 nuclear emulsion, stored with desiccant at $4^{\circ} \mathrm{C}$ for 5$20 \mathrm{~d}$, developed, and stained with hematoxylin and eosin for microscopic evaluation.

Control sense probes for PDE3A and PDE3B were used on parallel sections from embryos and most of the adult tissues (heart, kidney, liver, fat, and blood vessels) examined in this study and showed that background or nonspecific signal was extremely low (Figs. 1 and 2). Tissues from a minimum of two animals were evaluated at each time point studied and two to six anatomically matched sections from each sample were hybridized to each probe; the data which are reported are based on consistent observations in multiple tissue sections. In the developmental aspect of the study, embryo, postnatal, and adult tissues were prepared identically, hybridized with the same batch of labeled probe, washed, exposed, and developed together to facilitate comparison of signal level at the different stages.

\section{Results}

Anatomical patterns of PDE3A and PDE3B gene expression were evaluated in sagittal sections through entire E15 and E20 rat embryos. The basic patterns established at E15 are conserved at E20 and are shown in Fig. 1. PDE3A mRNA is most abundant in adipose tissue, including both brown and white fat (Figs. 1 and 2). It is expressed at lower levels in a diffuse pattern in lung and liver parenchyma and throughout the nervous system 

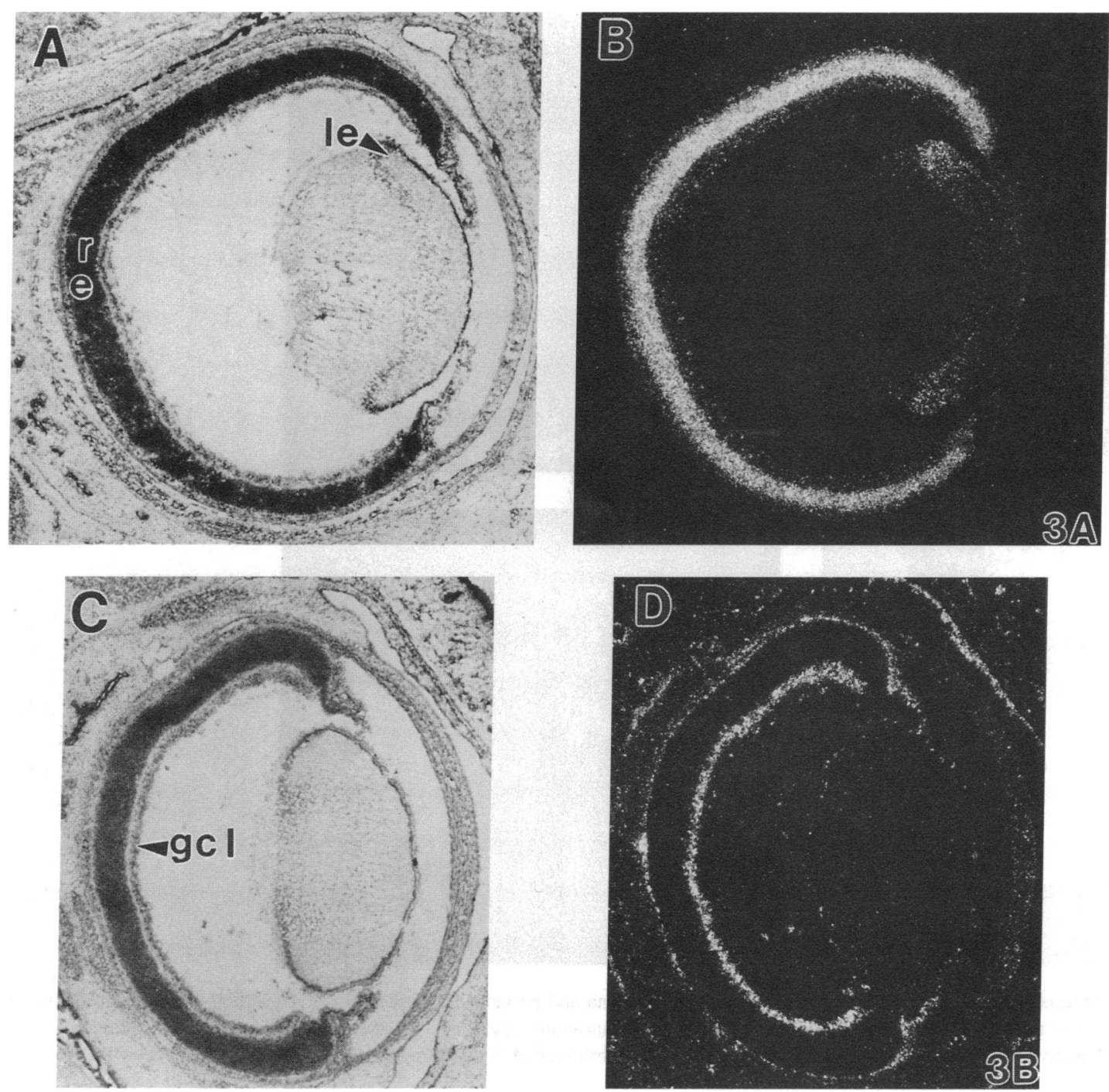

Figure 6. PDE3A and PDE3B exhibit very distinct cellular patterns of expression in the developing eye. PDE3A mRNA is concentrated in the neural retina $(r e)$ and bow region of the lens epithelium (le, $A$ and $B$ ). PDE3B mRNA is confined to the ganglion cell layer $(g c l, C$ and $D)$ where developing capillaries are found.

(Fig. $1 B$ ). PDE3B mRNA's distribution is clearly distinct from that of PDE3A (Fig. 1). It is most abundant in the gastrointestinal and cardiovascular systems (Fig. $1 C$ and Fig. 3,A-D). In the intestine, it is concentrated in the epithelium as well as developing smooth muscle. It is concentrated in the endothelium and smooth muscle of arteries and veins of all caliber (Fig. 3, $A-D)$. The high level of PDE3B mRNA hybridization in the E20 lung arises from the vasculature as well as bronchial smooth muscle and epithelium (Fig. 3, $C$ and $D$ ). PDE3B is also expressed in myocardium, first noted at E15 (Fig. 3, $E$ and $F$ ). PDE3A and PDE3B mRNAs are expressed in differential cell populations of the developing brain (Fig. 1, $B$ and $C$ ) and demonstrate distinct developmental regulation (data not shown, Reinhardt, R. R., and C. A. Bondy, manuscript in preparation). Nonspecific signal as assessed by hybridization of parallel sections with sense probes for each transcript was very low (Figs. $1, D$ and $E$, and $2, E$ and $F$ ).

PDE3B gene expression demonstrates a highly focal pattern in the developing liver. From E15, this mRNA is intensely concentrated in isolated large cells, which are clearly different from hepatocytes and the usual nonparenchymal hepatic cells.
The PDE3B-positive cells in embryonic liver are so large and the signal so intense that they are easily visible on film autoradiographs (Fig. $1 C$ ). These large cells appear multinucleated and thus are likely to be megakaryocytes which are present along with other hematopoietic cells in fetal liver. These cells are still found in the liver $5 \mathrm{~d}$ after birth (Fig. 4, $A$ and $B$ ) but disappear thereafter (Fig. 4, $C$ and $D$ ), at the same time that hepatic hematopoiesis ceases, leaving hepatic PDE3B mRNA detected only in endothelium. In contrast, PDE3A mRNA is diffusely expressed by hepatocytes without any apparent change from E15 through adult life (Fig. 4, $E$ and $F$ ). Expression patterns for PDE3A and PDE3B were stable over time in adipose tissue and vasculature, with PDE3A mRNA remaining highly abundant in adult fat (Fig. 5, $A$ and $B$ ) and PDE3B in adult vasculature (Fig. 5, $C$ and $D$ ).

PDE3A and PDE3B demonstrate very interesting patterns of expression in the developing eye (Fig. 6). PDE3A mRNA is highly abundant in the embryonic neural retina, which is composed of differentiating neuroepithelial cells (Fig. 6, $A$ and $B)$. This mRNA is also present in the bow region of the lens epithelium, where the epithelial cells are differentiating 

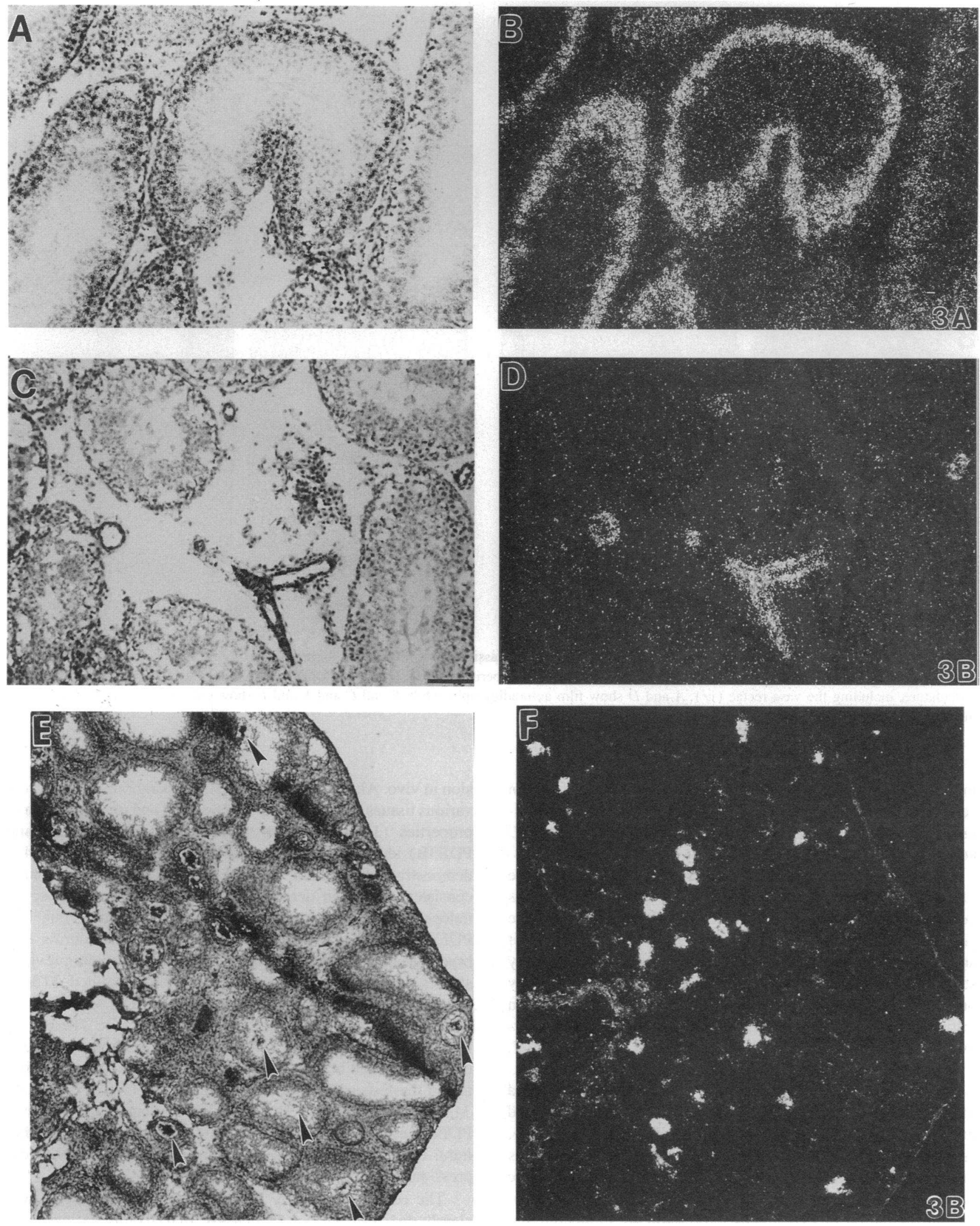

Figure 7. Comparison of PDE3A and PDE3B gene expression in mature rat testis. PDE3A mRNA is concentrated in primary spermatocytes $(A$ and $B$ ) while PDE3B is detected only in blood vessels $(C$ and $D)$. PDE3B mRNA is exceedingly abundant in rat oocytes, as shown in the prepubertal (postnatal day 20) ovary $(E$ and $F$ ). Arrowheads point to some of the PDE3B-positive oocytes in $E$. Bar $=100 \mu \mathrm{m}$ for $A-D$ and $200 \mu \mathrm{m}$ for $E$ and $F$. 

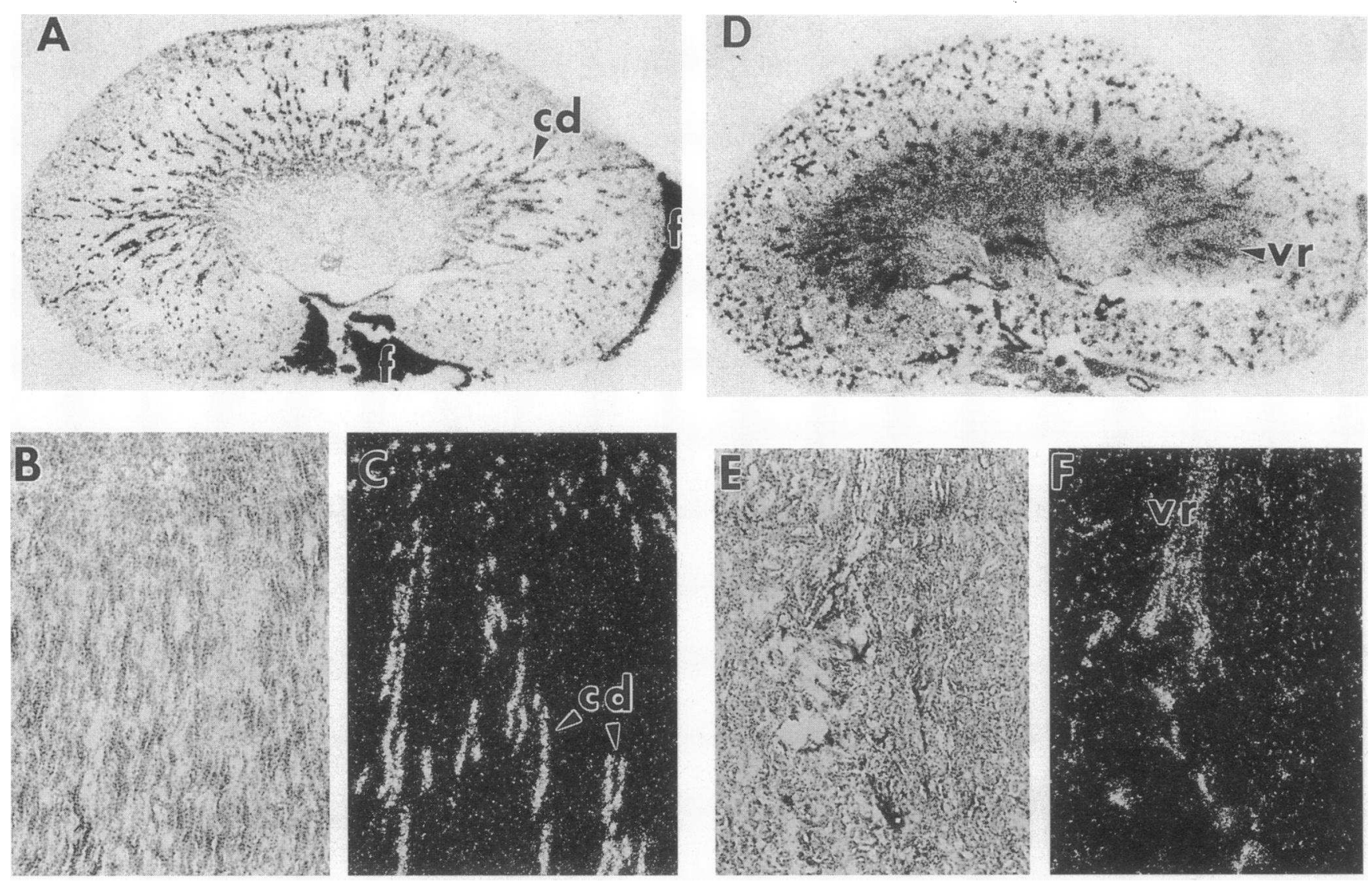

Figure 8. Comparison of PDE3A $(A-C)$ and PDE3B $(D-F)$ gene expression in the mature rat kidney. PDE3A mRNA is localized in collecting ducts $(c d)$ in the outer medulla and cortex and is also abundant in the perinephric fat $(f)(A)$. PDE3B mRNA is concentrated in the renal vasculature, including the vasa rectae (vr). $A$ and $D$ show film autoradiographs while $B$ and $C$ and $E$ and $F$ show paired bright- and dark-field micrographs.

into lens fibers. PDE3B mRNA is confined to the ganglion cell layer, where it seems to be primarily expressed by capillaries sprouting along the inner surface of the retina (Fig. 6, $C$ and $D$ ).

PDE3A and PDE3B mRNAs were also evaluated in the developing and mature rat testis. Very little PDE3A mRNA was detected until after puberty, when high levels appear in the germinal epithelium (Fig. 7, $A$ and $B$ ). The signal is most abundant in seminiferous tubule segments engaged in early stages of spermiogenesis where it is selectively expressed by primary spermatocytes. PDE3B mRNA was detected only in testicular blood vessels (Fig. 7, $C$ and $D$ ). Interestingly, however, PDE3B mRNA was highly abundant in oocytes (Fig. 7, $E$ and $F$ ).

Finally, PDE3A and PDE3B gene expression was compared in the mature rat kidney. PDE3A mRNA is selectively localized in cortical and outer medullary collecting ducts (Fig. 8, $A-C$ ), as well as perinephric fat (Fig. $8 A$ ), while PDE3B mRNA is prominently concentrated in the renal vasculature, including the vasa rectae (Fig. $8, D-F$ ). The tissue specificity and developmental regulation of PDE3 gene expression are compared and summarized in Table I.

\section{Discussion}

This is the first study to provide a comprehensive picture of the cell-specific and developmental patterns of PDE3 gene expres- sion in vivo. Although purified PDE3 preparations isolated from various tissues exhibit similar biochemical and pharmacological properties (11), these two PDE3 transcripts (PDE3A and PDE3B) identified by molecular cloning techniques $(40,41)$ demonstrate differential cellular patterns of gene expression consistent with their derivation from separate genes subject to independent regulation. The present results demonstrate that PDE3A mRNA is highly expressed in adipocytes during embryogenesis and throughout adult life, consistent with previous studies on cultured rat adipocytes and differentiated 3T3-L1 adipocytes (41). PDE3A mRNA is also stably expressed in liver, albeit at lower levels, through development. These findings are consistent with a functional role for insulin activation of adipocyte and hepatic PDE3s in regulation of hormone-stimulated lipolysis and perhaps glycogenolysis $(11,19,20,28,29$, $34-37,43-45)$. This study has also identified high level PDE3A gene expression in spermatocytes and in neuroepithelium, including the developing neural retina, where PDE3 expression had not been evaluated previously.

The cellular specificity of PDE3B mRNA expression was clearly distinct from that of PDE3A. PDE3B mRNA was most abundant in smooth muscle of vascular, bronchial, gastrointestinal, and genitourinary systems. PDE3 activities have been intensively studied in vascular and tracheo-bronchial smooth muscle where PDE3 inhibitors promote relaxation $(15-18,24)$. PDE3B mRNA was highly expressed in myocardium from the time of myocyte differentiation into adulthood, confirming pre- 
Table I. Cellular Distribution and Developmental Regulation of PDE3 Gene Expression

\begin{tabular}{lccc}
\hline \multicolumn{1}{c}{ Tissue } & PDE3A & PDE3B & $\begin{array}{c}\text { Developmental } \\
\text { regulation }\end{array}$ \\
\hline Adipocytes & +++ & + & No \\
Spermatocytes & ++ & - & Yes \\
Oocytes & + & +++ & No \\
Endothelium & - & ++ & No \\
Smooth muscle & - & ++ & No \\
Hepatocytes & + & - & No \\
Megakaryocytes & - & +++ & ND \\
Collecting ducts & ++ & - & No \\
Neuroepithelium & ++ & ++ & Yes \\
Bronchial, gastrointestinal, & & & ND \\
\multicolumn{1}{c}{ and urogenito-epithelium } & - & ++ & \\
& & &
\end{tabular}

Semiquantitative comparison of PDE3 mRNA abundance in different cell types and across developmental stages was carried out in tissues which were prepared, hybridized, washed, and exposed together. The rating of relative mRNA abundance applies primarily within the columns since there may be intrinsic differences in hybridization efficiency which make direct comparison of signal intensity generated by different probes problematical. Hybrid signal estimation: $(-)$ not above background, $(+)$ $2-5 \times$ background, $(++) 6-10 \times$ background, $(+++)>10 \times$ background or grains too numerous to count. Absence of developmental regulation means that stable mRNA levels were detected from the time the differentiated tissue first appeared through adulthood. PDE3s showed pronounced developmental regulation in the nervous system, where high levels were seen in early development (although in different cell types) followed by reduced expression in the mature nervous system. $N D$, not determined.

vious Northern hybridization data $(40,41)$, and in presumed megakaryocytes. In addition to the present evidence, the molecular relatedness of the cardiac and platelet PDE3 is supported by the fact that human PDE3B cDNA was cloned from a cardiac cDNA library using oligonucleotide probes based on the amino acid sequence of peptides isolated from proteolytic digests of purified human platelet PDE3 (40). Furthermore, the deduced sequence of the catalytic domain of the cardiac PDE3B cDNA is very similar to the partial peptide sequences obtained from the purified platelet PDE3 (40). PDE3 inhibitors serve both as potent inotropic agents (23-25) and inhibitors of platelet aggregation $(26,27,30)$ in humans, although they are much less effective in stimulating myocardial contractility in rats (46). While a role for PDE3B in smooth and cardiac muscle has been established, its function in vascular endothelium and respiratory and gastrointestinal epithelium, where this study has also demonstrated high level PDE3B gene expression, is as yet unknown.

PDE3B mRNA was also found to be highly expressed in rat oocytes. In frog (Xenopus) oocytes, insulin activation of a cAMP phosphodiesterase is associated with oocyte maturation and this process can be blocked by PDE3 inhibitors but not by type IV PDE (PDE4) inhibitors $(47,48)$. The role of PDE3s in oocytes and spermatocytes is unknown, but the high level of PDE3 gene expression in rat gametes suggests, if extrapolated to humans, that therapy with PDE3 inhibitors must consider potential effects on germ cells. Additionally, both PDE3B and PDE3A mRNAs are highly expressed and developmentally regulated in the nervous system. The two mRNAs are, however, expressed by different cell populations and exhibit different spatiotemporal profiles during development (Reinhardt, R. R., and C. A. Bondy, manuscript in preparation). Differential cellular patterns of expression of PDE subfamily members are not unique to the PDE3s, as shown in two recent in situ hybridization studies in adult rodent brain $(49,50)$ which demonstrated overlapping as well as distinctive neuronal patterns of expression of the 61- and 63-kD calmodulin-sensitive PDEs (PDE1), which are also products of different genes (5-7).

If the PDE3 steady state mRNA levels described in this study are found to correlate with cellular enzyme levels, it will suggest new layers of complexity to the regulation of cyclic nucleotide phosphodiesterases and will have significant implications as to their cellular functions. In addition to understanding mechanisms for cellular distribution and regulation of the seven different PDE gene subfamilies (1-3), similar consideration must now be extended to individual PDE subfamily members. PDE3A and PDE3B each represent distinct gene products which exhibit differential jurisdictions and which presumably will be subject to different cell-specific mechanisms for regulation of gene expression. Previous physiological data combined with the present anatomical information suggest that PDE3B has a unified function in regulation of cyclic nucleotide levels in visceral smooth muscle, platelets, and myocardium, while PDE3A primarily contributes to regulating cyclic nucleotide levels in adipocytes and hepatocytes. Thus PDE3A is probably devoted primarily to regulation of insulin-induced lipolysis and glycogenolysis while PDE3B is involved in hormonal regulation of myocardial and smooth muscle contractility and platelet aggregation. Our observations, taken together with those of others concerning the distribution of mRNA of calmodulin-sensitive PDEs in brain $(49,50)$, support the view that PDE subfamily members serve specific functional roles. The possibility that these two PDE3s have discrete, tissue-specific functional roles has implications for development of therapeutic agents, in terms of targeting drug delivery to specific cell types and the development of inhibitors selective for specific phosphodiesterases.

\section{Acknowledgments}

The authors wish to thank Mr. Ricardo Dreyfuss for photographic expertise, Mr. Steven Hockman for his technical expertise, and Mrs. Carol Kosh for her secretarial assistance.

\section{References}

1. Bentley, J. K., and J. A. Beavo. 1992. Regulation and function of cyclic nucleotides. Curr. Opin. Cell Biology. 4:233-240.

2. Conti, M., S. L. C. Jin, L. Monaco, D. R. Repaske, and J. V. Swinnen. 1991. Hormonal regulation of cyclic nucleotide phosphodiesterases. Endocr. Rev. 12:218-234.

3. Michaeli, T., T. J. Bloom, T. Martin, K. Loughney, K. Ferguson, M. Riggs, L. Rodgers, J. A. Beavo, and M. Wigler. 1993. Isolation and characterization of a previously undetected human cAMP phosphodiesterase by complementation of a cAMP deficient Saccharomyces cerevesiae. J. Biol. Chem. 268:12925-12932.

4. Charbonneau, H. 1990. Structure-function relationships among cyclic nucleotide phosphodiesterases. In Cyclic Nucleotide Phosphodiesterases: Structure, Regulation, and Drug Action. J. A. Beavo and M. D. Houslay, editors. J. Wiley and Sons, Chichester, United Kingdom. 267-298.

5. Wang, J. H., R. K. Sharma, and M. J. Moorbrock. 1990. Calmodulinstimulated cyclic nucleotide phosphodiesterases. In Cyclic Nucleotide Phosphodiesterases: Structure, Regulation, and Drug Action. J. A. Beavo and M. D. Houslay, editors. J. Wiley and Sons, Chichester, United Kingdom. 19-60.

6. Bentley, J. K., A. Dadlecek, C. Sherber, D. Seger, W. K. Sonnenberg, H. Charbonneau, J. P. Novack, and J. A. Beavo. 1992. Molecular cloning of cDNA encoding a " $63 \mathrm{kDa}$ " calmodulin-dependent phosphodiesterase from bovine brain. J. Biol. Chem. 267:18676-18682.

7. Sonnenberg, W. K., D. Seger, and J. A. Beavo. 1993. Molecular cloning 
of a cDNA encoding the "61-kDa" calmodulin-stimulated cyclic nucleotide phosphodiesterase. J. Biol. Chem. 268:645-652.

8. Swinnen, J. V., D. R. Joseph, and M. Conti. 1989. Molecular cloning of rat homologues of the Drosophila melanogaster dunce cAMP phosphodiesterase: evidence of a family of genes. Proc. Natl. Acad. Sci. USA. 86:5325-5329.

9. Bolger, G., T. Michaeli, T. Martins, T. St. John, B. Steiner, L. Rodgers, M. Riggs, M. Wigler, and K. Ferguson. 1993. A family of human phosphodiesterases homologous to the dunce learning and memory gene product of Drosophila melanogaster are potential targets for antidepressant drugs. Mol. Cell. Biol. 13:65586571.

10. MacFarland, R. T., B. D. Zelus, and J. A. Beavo. 1991. High concentrations of a cGMP-stimulated phosphodiesterase mediate ANP-induced decreases in cAMP and steroidogenesis in adrenal glomerulosa cells. J. Biol. Chem. 266:136142.

11. Manganiello, V. C., C. J. Smith, E. Degerman, and P. Belfrage. 1990. Cyclic GMP-inhibited cyclic nucleotide phosphodiesterases. In Cyclic Nucleotide Phosphodiesterases: Structure, Regulation, and Drug Action. J. A. Beavo and M. D. Houslay, editors. J. Wiley \& Sons, Chichester, United Kingdom. 87-117.

12. Degerman, E., P. Belfrage, A. H. Newman, K. Rice, and V. C. Manganie1lo. 1987. Purification of the putative hormone-sensitive cyclic cAMP phosphodiesterase from adipose tissue using a derivative of cilostamide as a novel affinity ligand. J. Biol. Chem. 262:5797-5807.

13. Grant, P., and R. Colman. 1984. Purification and characterization of a human platelet cyclic nucleotide phosphodiesterase. Biochemistry. 23:1801-1807.

14. Harrison, S. A., D. H. Reifsnyder, B. Gallis, G. G. Cadd, and J. A. Beavo. 1986. Isolation and characterization of bovine cardiac muscle cGMP-inhibited phosphodiesterases: a receptor for new cardiotonic drugs. Mol. Pharmacol. 29:506-514

15. Rascon, A., S. Lindgren, L. Stavenow, P. Belfrage, K. E. Andersson, V. C. Manganiello, and E. Degerman. 1992. Purification and properties of cGMP-inhibited cAMP phosphodiesterase from bovine aortic smooth muscle. Biochim. Biophys. Acta. 1134:149-156.

16. Silver, P. B. R. E. Lepore, B. O'Connnor, B. Lemp, L. T. Hamel, R. G. Bentley, and A. L. Harris. 1988. Inhibition of the low $K_{\mathrm{m}}$ cyclic AMP phosphodiesterase and activation of the cyclic AMP system in vascular smooth muscle By milrinone. J. Pharmacol. Exp. Ther. 247:34-42.

17. Harris, A., M. J. Connell, E. W. Ferguson, A. M. Wallace, R. J. Gordon, E. D. Pagani, and P. J. Silver. 1989. Role of low $K_{\mathrm{m}}$ cyclic AMP phosphodiesterase inhibition in tracheal relaxation and bronchodilation in the guinea pig. J. Pharmacol. Exp. Ther. 251:199-206.

18. Torphy, T. J., B. J. Undem, L. B. Cieslinski, M. A. Luttmann, M. L. Reeves, and D. W. P. Hay. 1993. Identification, characterization and functional role of phosphodiesterase isozymes in human airway smooth muscle. J. Pharmacol. Exp. Ther. 265:1213-1223.

19. Pyne, N., M. E. Cooper, and M. D. Houslay. 1987. The insulin and glucagon-stimulated dense vesicle high-affinity cyclic AMP phosphodiesterase from rat liver. Biochem. J. 242:33-42.

20. Boyes, S., and E. G. Loten. 1988. Purification of an insulin-sensitive cyclic AMP phosphodiesterase from rat liver. Eur. J. Biochem. 174:303-309.

21. LeBon, T. R., I. Kasuya, R. J. Paxton, P. Belfrage, S. Hockman, V. C. Manganiello, and Y. Fujita-Yamaguchi. 1992. Purification and characterization of cGMP-inhibited low $K_{\mathrm{m}}$ phosphodiesterase from human placenta cytosolic fractions. Endocrinology. 130:3265-3274.

22. Robicsek, S. A., D. K. Blanchard, J. Y. Djeu, J. J. Krzanowski, A. Szentwanji, and J. B. Polson. 1991. Multiple high-affinity cAMP-phosphodiesterases in human T-lymphocytes. Biochem. Pharmacol. 42:869-877.

23. Colucci, W., R. F. Wright, and E. Braunwald. 1986. New positive inotropic agents in the treatment of congestive heart failure. N. Engl. J. Med. 314:349358.

24. Ludmer, P. L., R. F. Wright, M. O. Arnold, P. Ganz, E. Braunwald, and W. S. Colucci. 1986. Separation of the direct myocardial and vasodilator action of milrinone administered by an intracoronary infusion technique. Circulation. 73:130-137.

25. Colucci, W. 1993. Search for effective and safe orally active positive inotropic drugs for the treatment of heart failure. Cardiol. Rev. 1:42-49.

26. Alvarez, R., G. L. Banerjee, J. J. Bruno, G. L. Jones, K. Littschwager, A. Strossberg, and M. C. Venuti. 1986. A potent and selective inhibitor of cyclic AMP phosphodiesterase with potential cardiotonic and anti-thrombotic properties. Mol. Pharmacol. 29:554-560.

27. Simpson, A. W. M., M. L. Reeves, and T. J. Rink. 1988. Effects of SK and F94120, an inhibitor of cyclic nucleotide phosphodiesterase type III, on human platelets. Biochem. Pharmacol. 37:2315-2320.

28. Kono, T., F. W. Robinson, and J. A. Sarver. 1975. Insulin-sensitive phosphodiesterase: its location, hormonal stimulation, and oxidative stabilization. $J$. Biol. Chem. 250:7826-7835.

29. Boyes, S., and E. G. Loten. 1989. Insulin and lipolytic hormones stimulate the same phosphodiesterase isoform in rat adipose tissue. Biochem. Biophys. Res. Commun. 162:814-820.

30. MacPhee, C. H., S. H. Harrison, and J. A. Beavo. 1986. Immunological identification of the major platelet low $K_{\mathrm{m}}$ cAMP phosphodiesterase: probable target for anti-thrombotic agents. Proc. Natl. Acad. Sci. USA. 83:6660-6663.

31. Kauffman, R. F., G. Crowe, B. Utterback, and D. W. Robertson. 1987. LY195115: a potent, selective inhibitor of cyclic nucleotide phosphodiesterase located in the sarcoplasmic reticulum. Mol. Pharmacol. 30:609-616.

32. Lugnier, C., B. Muller, A. LeBec, C. Beaudry, and E. Rousseau. 1993. Characterization of indolidan- and rolipram-sensitive cyclic nucleotide phosphodiesterases in canine and human cardiac microsomal fractions. J. Pharmacol. Exp. Ther. 265:1142-1151.

33. Kithas, P. A., M. Artman, W. J. Thompson, and S. S. Strada. 1989. Subcellular distribution of cyclic AMP phosphodiesterase activities in rabbit ventricular myocardium: relation to post-natal maturation. J. Mol. Cell. Cardiol. 21:507-517.

34. Manganiello, V. C., C. J. Smith, E. Degerman, V. Vasta, H. Tornqvist, and P. Belfrage. 1991. Molecular mechanisms involved in the antilipolytic action of insulin: phosphorylation and activation of a particulate cAMP phosphodiesterase. Adv. Exp. Med. Biol. 293:239-248.

35. Beltman, J., W. K. Sonnenberg, and J. A. Beavo. 1993. The role of protein phosphorylation in the regulation of cyclic nucleotide phosphodiesterases. Mol. Cell. Biochem. 127/128:239-253.

36. Schmitz-Peifer, C., M. L. Reeves, and R. M. Denton. 1992. Characterization of the cyclic nucleotide phosphodiesterase isoenzymes in rat epididymal fat cells. Cell. Signalling. 4:37-49.

37. Beebe, S. J., J. B. Redmon, P. F. Blackmore, and J. D. Corbin. 1985 Discriminative insulin antagonism of stimulatory effects of various cAMP analogs on adipocyte lipolysis and hepatocyte glycogenolysis. J. Biol. Chem. 260:22262233.

38. Maurice, D. W., and R. J. Haslam. 1990. Molecular basis of the synergistic inhibition of platelet function by nitrovasodilators and activators of adenylate cyclase: inhibition of cAMP breakdown by cGMP. Mol. Pharmacol. 37:671-681.

39. Marcoz, P., A. F. Prigent, M. Lagarde, and G. Nemoz. 1993. Modulation of rat thymocyte proliferative response through inhibition of different cyclic nucleotide phosphodiesterase isoforms by means of selective inhibitors and cGMPelevating agents. Mol. Pharmacol. 44:1027-1035.

40. Meacci, E., M. Taira, M. Moos, Jr., C. J. Smith, M. A. Movsesian, E. Degerman, P. Belfrage, and V. C. Manganiello. 1992. Molecular cloning and expression of human myocardial cGMP-inhibited cAMP phosphodiesterase. Proc. Natl. Acad. Sci. USA. 89:3721-3725.

41. Taira, M., S. Hockman, J. C. Calvo, M. Taira, P. Belfrage, and V. C. Manganiello. 1993. Molecular cloning of the adipocyte hormone-sensitive cyclic GMP-inhibited cyclic nucleotide phosphodiesterase. J. Biol. Chem. 268:1857318579.

42. Bondy, C. A., J. Zhou, and W. H. Lee. 1993. In situ hybridization histochemistry. In Handbook of Endocrine Research Techniques. F. de Pablo and C. G. Scanes, editors. Academic Press, New York. 266-288.

43. Loten, E. G., and J. G. T. Sneyd. 1970. An effect of insulin on adipose tissue adenosine 3'5'-cyclic monophosphate phosphodiesterase. Biochem. J. 120:187-193.

44. Loten, E. G., F. D. Assimacopoulos-Jeannet, J. H. Exton, and C. R. Park. 1978. Stimulation of a low $K_{\mathrm{m}}$ phosphodiesterase from liver by insulin and glucagon. J. Biol. Chem. 253:746-757.

45. Houslay, M. D., and E. Kilgour. 1990. Cyclic nucleotide phosphodiesterases in liver: a review of their characterization, regulation by insulin and glucagon and their role in controlling intracellular cyclic AMP concentrations. In Cyclic Nucleotide Phosphodiesterases: Structure, Regulation, and Drug Action. J. A Beavo and M. D. Houslay. John Wiley and Sons, Ltd., Chichester, United Kingdom. $185-224$

46. Katano, Y., and M. Endoh. 1992. Effects of a cardiotonic quinolinone derivative Y-20487 on the isoproterenol-induced positive inotropic action and cyclic AMP accumulation in rat ventricular myocardium: comparison with rolipram, RO 20-1724, milrinone, and isobutylmethylxanthine. J. Cardiovasc. Pharmacol. 20:715-722.

47. Sadler, S. E., and J. L. Maller. 1989. In vivo regulation of cyclic AMP phosphodiesterase in Xenopus oocytes: stimulation by insulin and insulin-like growth factor. J. Biol. Chem. 264:856-861.

48. Sadler, S. E. 1991. Type III phosphodiesterase plays a necessary role in the growth promoting actions of insulin, insulin-like growth factor-1 and Ha 21 ras in Xenopus laevis oocytes. Mol. Endocrinol. 5:1939-1946.

49. Yan, C., J. K. Bentley, W. Sonnenberg, and J. A. Beavo. 1994. Differential expression of the $61 \mathrm{kDa}$ and $63 \mathrm{kDa}$ calmodulin-dependent phosphodiesterases in the mouse brain. J. Neurosci. 14:973-984.

50. Polli, J. W., and R. Kincaid. 1994. Expression of a calmodulin-dependent phosphodiesterase isoform (PDE 1B1) correlates with brain regions having extensive dopaminergic innervation. J. Neurosci. 14:1251-1261. 